\title{
North Atlantic right whale occurrence near wind energy areas along the mid-Atlantic US coast: implications for management
}

\author{
Kristin B. Hodge ${ }^{1}$, Charles A. Muirhead ${ }^{1}$, Janelle L. Morano ${ }^{1,2}$, \\ Christopher W. Clark ${ }^{1}$, Aaron N. Rice ${ }^{1 *}$ \\ ${ }^{1}$ Bioacoustics Research Program, Cornell Lab of Ornithology, Cornell University, Ithaca, NY 14850, USA \\ ${ }^{2}$ Present address: Macaulay Library, Cornell Lab of Ornithology, Cornell University, Ithaca, NY 14850, USA
}

\begin{abstract}
The distribution and seasonal patterns of the North Atlantic right whale, Eubalaena glacialis, inform management decisions that mitigate anthropogenic threats. Based on data from visual surveys, much of the population migrates between winter calving grounds in coastal waters adjacent to the southeast USA and summer feeding and nursery grounds adjacent to the northeast USA. However, little is known about right whale occurrence along the mid-Atlantic US migratory corridor. A better understanding of right whale occurrence in this region is needed prior to offshore wind energy development activities, which may increase mortality risks and chronic impacts on the population. We conducted an 11 mo passive acoustic survey along coastal North Carolina and Georgia near several wind energy areas to document the acoustic occurrence of right whales in the southern region of the mid-Atlantic US coast. Right whales were acoustically detected across all seasons, with peak seasonal presence occurring during autumn in the Georgia site and during winter in the North Carolina site. A secondary peak in presence also occurred during June and July in the Georgia site, when right whales were not expected to be in the area. Given the nearly year-round presence of right whales in the survey areas, these results may warrant an evaluation of current management protocols in order to provide adequate protection to the population in the face of offshore energy development activities.
\end{abstract}

KEY WORDS: Eubalaena glacialis - Passive acoustic monitoring · Mid-Atlantic $\cdot$ Seasonality · Distribution · Management

\section{INTRODUCTION}

The North Atlantic right whale, Eubalaena glacialis, is one of the most endangered whale species in the world and is protected by the Endangered Species Act and the Marine Mammal Protection Act (Clapham et al. 1999, Waring et al. 2013). Currently, the western North Atlantic population consists of $\sim 400$ to 500 individuals (Pettis 2013, Waring et al. 2013). Despite a recent positive trend in population growth estimates, this population continues to exhibit a slow and difficult recovery due to its low population size, low reproductive rates, and expo-

${ }^{*}$ Corresponding author: arice@cornell.edu sures to anthropogenic threats (Fujiwara \& Caswell 2001, Kraus et al. 2005, 2007, Waring et al. 2013). Ship strikes and entanglement with fishing gear are the leading causes of human-induced mortality for this population, and sub-lethal threats, such as noise pollution, may potentially disrupt biologically relevant behaviors (Kraus 1990, Knowlton \& Kraus 2001, Parks \& Clark 2007, Clark et al. 2009, Cassoff et al. 2011, Hatch et al. 2012).

The US National Marine Fisheries Service (NMFS) has implemented protective measures to mitigate anthropogenic threats to right whales (NMFS 2005), including designating seasonal management areas

(C) The authors 2015. Open Access under Creative Commons by Attribution Licence. Use, distribution and reproduction are unrestricted. Authors and original publication must be credited.

Publisher: Inter-Research · www.int-res.com 
(SMAs) along the southeast, mid-Atlantic, and northeast coastal waters of the western North Atlantic. One of these measures requires that vessels $\geq 65 \mathrm{ft}$ $(19.8 \mathrm{~m})$ reduce speeds during seasons when right whales are likely to be present in the area (NOAA 2008). Although reducing vessel speed decreases the risk of ship strike mortality (Laist et al. 2001, Vanderlaan \& Taggart 2007, Wiley et al. 2011, Conn \& Silber 2013), current mitigation efforts may not provide adequate protection due to incomplete spatial and temporal coverage of right whale habitat and occurrence (Schick et al. 2009, van der Hoop et al. 2013, 2015). Since the efficacy of current management protocols is uncertain, regulatory efforts require ongoing evaluation and modification (Pace 2011, van der Hoop et al. 2013, 2015).

NMFS designated right whale critical habitats in order to protect and manage geographic areas important for right whale conservation (NOAA 1994). The US Endangered Species Act defines critical habitat as a geographic area that contains physical and biological features important for life processes and reproduction, which may include breeding and calving grounds, feeding sites, and representative habitats of the historical distribution of a species (NOAA 1994). Currently, protected right whale habitats include calving areas along the coasts of Florida and Georgia, as well as feeding areas in the Great South Channel (southeast of Cape Cod), Massachusetts Bay, and Cape Cod Bay (NOAA 1994). Since calving and feeding events have been documented outside of critical habitat boundaries (Patrician et al. 2009, Foley et al. 2011, Whitt et al. 2013), other areas may also be ecologically important regions for the right whale population. However, these other known right whale areas of seasonal residency are not afforded the same protections as critical habitats. Thus, efforts to conserve right whales may be diminished if they are not protected within the migratory corridor between critical habitat areas (NMFS 2005). Therefore, regulations have been proposed to expand critical habitat boundaries (NOAA 2010).

Understanding right whale distribution and seasonal migratory patterns is an essential component of effective management practices. Based on data from visual surveys, right whale seasonal movements are characterized by a round-trip migration in nearshore waters along the western North Atlantic (Winn et al. 1986). During their migration cycle, right whales aggregate in Florida and Georgia calving grounds during winter; migrate through mid-Atlantic coastal waters during late winter and early spring; enter northern feeding grounds in Cape Cod Bay, Massa- chusetts Bay, and the Great South Channel during spring; aggregate in the Bay of Fundy and Scotian Shelf feeding grounds during summer and early autumn; and return south during the winter (Kraus et al. 1986, Winn et al. 1986, Kenney et al. 1995, 2001). Although this migration pattern explains the distribution of much of the right whale population, recent acoustic studies have detected right whales at times of the year when their occurrence in a region was not previously expected. For instance, Morano et al. (2012) and Whitt et al. (2013) documented right whale occurrence yearround in Massachusetts Bay and off the New Jersey coast, respectively, while Mellinger et al. (2007) detected right whale calls on the Scotian Shelf in late December, when much of the population would be predicted to have left for more southerly areas. Similarly, the aerial survey study by Cole et al. (2013) documented right whales in the central Gulf of Maine between November and January. These observations suggest seasonal migratory movements may not be representative of the entire population, because only a subset of the population (predominately reproductive females, calves, and juveniles) are observed traveling along the migratory corridor between calving and feeding grounds (Kraus et al. 1986, Winn et al. 1986), and it is not known where the remaining members of the population spend the winter (Kraus et al. 1986, Winn et al. 1986). Given these findings, investigating right whale spatial and temporal patterns along the right whale's migratory route, particularly in regions where movement patterns are not well understood, could help inform management decisions.

The coastal waters of North Carolina and Georgia are part of the mid-Atlantic habitat for endangered whale species, including right whales (Waring et al. 2013). Little is understood about right whale spatial and temporal occurrence in this region due to limited systematic visual survey efforts (Knowlton et al. 2002, Firestone et al. 2008, NMFS 2012), yet this region has some of the heaviest vessel traffic along the eastern seaboard and is considered the region of highest risk for vessel-strike mortality (Knowlton et al. 2002, Silber \& Bettridge 2010, van der Hoop et al. 2013). Currently, areas along coastal North Carolina and Georgia have been identified or are being considered for offshore wind energy development (BOEM $2012 a, b, c)$, which could increase the exposure of whales to vessel traffic and the risks of injury or mortality (van der Hoop et al. 2012). Development activities, including construction and site surveys, would also introduce disturbances that could cause acoustic masking, hearing impairment, or physiological or behavioral stress (Madsen et al. 2006, Clark 
et al. 2007, Weilgart 2007, Rolland et al. 2012). Given that right whales are susceptible to these threats, information regarding right whale occurrence is needed to minimize potential impacts of offshore energy development activities.

We performed an 11 mo passive acoustic survey to characterize right whale occurrence in 2 sites along the North Carolina and Georgia coasts near several wind energy areas. In this paper, we summarize the spatial and temporal patterns of right whale occurrence in the mid-Atlantic US migratory corridor, and we discuss the management implications of our findings with respect to mitigating threats introduced by offshore energy development.

\section{MATERIALS AND METHODS}

\section{Sound recording}

Acoustic data were collected using Marine Autonomous Recording Units (MARUs) (Calupca et al. 2000). MARUs were deployed at 2 sites along the mid-Atlantic coast of the US, hereafter referred to as the 'North Carolina' and 'Georgia' sites (Fig. 1). At the North Carolina site, 3 MARUs were deployed in a linear formation (extending NE-SW) in a location originally considered by the Bureau of Ocean Energy Management (BOEM) in 2009 as a possible wind energy area in Onslow Bay (in the Beaufort Lease Block, NI18-04), outside of the mid-Atlantic SMA (effective 1 November-30 April) and near the port of Morehead City. The Georgia site, also comprised of 3 MARUs in a linear formation, was centered on a wind energy area located within the southernmost part of the mid-Atlantic SMA, $80 \mathrm{~km}$ north of designated right whale critical habitat (in the Brunswick Lease Block, NH17-02, sub-block 6126). The closest distance between MARUs was $\sim 35 \mathrm{~km}$ for the North Carolina site and $18 \mathrm{~km}$ for the Georgia site, and seafloor depths were comparable within research sites (Table 1). The acoustic detection range of a MARU varies depending on environmental conditions, and although no empirical tests were conducted during the course of these deployments, we estimated the maximum detection range for right whales was between $9-25 \mathrm{~km}$
Table 1. Geographical coordinates and depths of marine autonomous recording units (MARUs) deployed at the North Carolina (NC) and the Georgia (GA) sites

\begin{tabular}{|lcccc|}
\hline Sites & MARU & $\begin{array}{c}\text { Latitude } \\
\left({ }^{\circ} \mathrm{N}\right)\end{array}$ & $\begin{array}{c}\text { Longitude } \\
\left({ }^{\circ} \mathrm{W}\right)\end{array}$ & $\begin{array}{c}\text { Depth } \\
(\mathrm{m})\end{array}$ \\
\hline North Carolina & & & \\
& NC-N & 34.3927 & 76.2356 & 31 \\
& NC-C & 34.1741 & 76.5098 & 34 \\
Georgia & NC-S & 33.9613 & 76.7925 & 38 \\
& GA-N & 31.9922 & 80.5970 & 14 \\
& GA-C & 31.8640 & 80.7207 & 14 \\
& GA-S & 31.7463 & 80.8544 & 14 \\
\hline
\end{tabular}

based on previous studies (McDonald \& Moore 2002, Clark et al. 2010).

Data were collected over the course of 2 consecutive deployments at each site, spanning 12 June-10 November 2012 and 12 November 2012-15 April 2013 at the North Carolina site, and 9 June-8 November 2012 and 10 November 2012-12 April 2013 at the Georgia site. A total of 307 consecutive days were recorded at

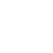

Fig. 1. Deployment locations of marine autonomous recording units (MARUs) at the (a) North Carolina (NC) and (b) Georgia (GA) sites, with respect to critOcean Energy Management (BOEM) wind energy areas (Kitty Hawk [KH], Wilmington East [WE], and Wilmington West [WW] areas). For reference, Wilmington East, $160 \mathrm{~km}$ E-NE of Wilmington West, and $210 \mathrm{~km}$ S-SW of located in the middle of the GA wind energy area (lease sub-block 6126) 
each site, with the exception of 11 November 2012 in North Carolina and 9 November 2012 in Georgia, when MARUs were replaced for the following deployment. Each MARU recorded continuously at a $2 \mathrm{kHz}$ sampling rate with high-pass and low-pass filters set at 10 and $800 \mathrm{~Hz}$, respectively. The high-pass filter was implemented to reduce electrical interference produced by the MARU, while the low-pass filter reduced aliasing. Each recorder had a flat frequency response $( \pm 2.0 \mathrm{~dB})$ in the $15-585 \mathrm{~Hz}$ band, which includes the frequency bands in which right whale sounds occur.

\section{Acoustic analysis}

Data were examined with a multi-stage feature vector testing automated detection algorithm (Urazghildiiev et al. 2009) designed to detect the presence of contact calls ('up-calls'), the most common call type for right whales (e.g. Clark 1982, Parks \& Tyack 2005). Automated detection events were visually reviewed in $10-450 \mathrm{~Hz}$ spectrograms in the MATLAB-based software program XBAT (Figueroa \& Robbins 2008, Bioacoustics Research Program 2012), with a 512point (256 ms) Hann window and $75 \%$ overlap (frequency resolution of $3.91 \mathrm{~Hz}$, time resolution of $64 \mathrm{~ms}$ ), for the occurrence of right whale up-calls. Each automated detection was reviewed until trained analysts validated the occurrence of one right whale up-call per day for each MARU at each site. All automated detection events were reviewed during days when right whale up-calls were not present to confirm that there was no acoustic evidence of whales in the area. Each validated detection was verified by a second trained analyst to confirm the occurrence of one right whale up-call per day per site.

We applied the following quantitative and qualitative criteria to distinguish up-calls from other biological and anthropogenic sounds based on a synthesis of Clark (1982) and Parks \& Tyack (2005): (1) starting frequency occurred between $65-170 \mathrm{~Hz}_{i}(2)$ minimum and maximum frequencies differed by $65-$ $200 \mathrm{~Hz}_{i}(3)$ duration ranged from $0.3-1.3 \mathrm{~s}_{i}$ (4) energy was concentrated in the lower portion of the signal; and (5) signal contour sloped upward (Fig. 2). Since humpback whales Megaptera novaeangliae occur in the mid-Atlantic US (Barco et al. 2002, Waring et al. 2013) and are known to produce upsweeps similar to right whale up-calls (Van Parijs et al. 2009), analysts browsed $5 \mathrm{~min}$ before and after each automated detection for the presence of humpback whale vocalizations. Humpback whale sounds were distin-

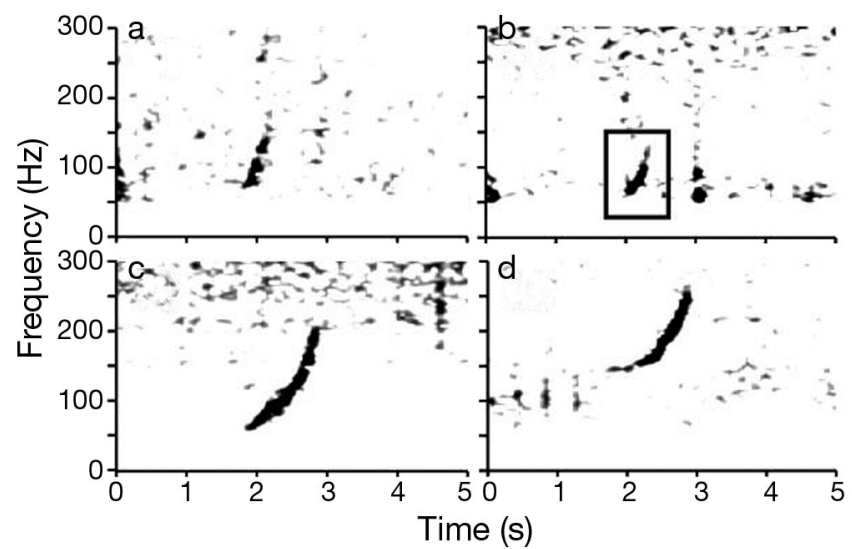

Fig. 2. Example spectrograms of right whale contact calls ('up-calls') recorded at the Georgia site on (a) 28 June 2012, (b) 13 July 2012, (c) 14 October 2012, and (d) 3 January 2013. Selection box in (b) distinguishes the contact call from adjacent noise. A high-pass filter at $50 \mathrm{~Hz}$ was used to eliminate low-frequency noise in these examples (512 point fast Fourier transform [FFT], Hann window, and $75 \%$ overlap, $3.9 \mathrm{~Hz}$ frequency resolution, $64 \mathrm{~ms}$ time resolution)

guished from right whale up-calls following the criteria listed in Mussoline et al. (2012), and questionable calls were excluded from our analysis.

Daily presence of right whales at each site was determined as the occurrence of at least one up-call per day on at least one MARU per site. Percent daily presence during each month was normalized for recording effort by dividing the number of days containing up-calls by the number of recording days within the month. To represent presence seasonally, months were grouped into seasons based on a synthesis of astronomical data and the seasonal right whale migration described in Winn et al. (1986), and the number of days containing up-calls within a season was divided by the total number of days containing up-calls. Seasons were defined as follows: summer (July-September 2012), autumn (OctoberDecember 2012), winter (January-March 2013), and spring (June 2012 and April 2013). To determine the proportion of daily presence that occurred while the mid-Atlantic SMA was in effect, we divided the number of days containing up-calls during the 1 November-30 April period by the total number of days in the recording period that contained up-calls.

\section{Acoustic detector evaluation}

In order to evaluate the performance of the detection algorithm, a truth data set was created by manually reviewing 40 randomly selected days, $20 \mathrm{~d}$ from each site, in XBAT for the presence of right 
whale up-calls. The truth data set was compared to the automated detection algorithm results in order to determine the number of true detections and missed detections from the detection algorithm; the probability of true detections and the probability of missed detections were calculated to evaluate detector performance (Table 2). Since we used a supervised detection approach (meaning all individual detection events were validated by expert analysts), the percent probability of missed detections is much more important for establishing whale occurrence; a high false alarm rate results in an increased time dedicated to analysis, but would not necessarily impact the ecological interpretation of daily presence. A Kruskal-Wallis test was performed in JMP Pro 10 (SAS) to determine if there was a significant difference in detection probability between the North Carolina site and the Georgia site.

\section{RESULTS}

Right whale up-calls were acoustically detected in both the North Carolina and Georgia survey areas throughout the recording period. These calls were acoustically detected on $20 \mathrm{~d}(6.5 \%)$ in the North Carolina site and $77 \mathrm{~d}(25.1 \%)$ in the Georgia site out of the total $307 \mathrm{~d}$ surveyed.

\section{Acoustic detector performance}

In the 20 randomly sampled days for each site, there were totals of 401 true up-calls in North Carolina and 515 true up-calls in Georgia. The automated detection algorithm determined a total number of 8319 up-call detections in the North Carolina site, and 9712 up-call detections in the Georgia site.

Table 2. Performance of the automated detection algorithm used to detect North Atlantic right whale contact calls ('upcalls') for the North Carolina and Georgia sites based on 20 randomly chosen days at each site. Total up-calls = true detections (TD) found by the automated detection algorithm + missed detections (MD) found by the human analyst. Performance measures include the TD and MD rate

\begin{tabular}{|lcc|}
\hline & North Carolina & Georgia \\
\hline Total up-calls & 401 & 515 \\
True detections & 256 & 239 \\
True detection rate & $63.8 \%$ & $46.4 \%$ \\
$\quad$ (TD/TD+MD) & 145 & 276 \\
Missed detections & $36.2 \%$ & $53.6 \%$ \\
Missed detection rate & & \\
(MD/TD+MD) & & \\
\hline
\end{tabular}

When compared to the truth dataset, only a fraction of the automated detections were true right whale up-calls, resulting in a true detection rate of $63.8 \%$ for the North Carolina site and $46.4 \%$ for the Georgia site (Table 2). There was no significant difference in detector performance between the North Carolina site and the Georgia site (Kruskal-Wallis, $S=382, Z=$ $-0.97841, p=0.3279)$. Since the true detection rate and missed detection rate are inversely related, the detector missed approximately a third of the total number of true up-calls for the North Carolina site and approximately half for the Georgia site (Table 2). However, when the detection algorithm was evaluated at a daily occurrence level of resolution (as the data are reported), the algorithm found $\geq 95 \%$ of the days for both sites in which right whale up-calls were present $(100 \%$ for the North Carolina site, $95 \%$ for the Georgia site). While the detector misses individual calls, it only missed $\leq 5 \%$ of days with up-calls present in the dataset; consequently, the detector had a low probability of missing the daily occurrence of right whales in either the North Carolina or Georgia survey areas (following Mellinger 2004).

\section{Right whale occurrence}

For the North Carolina site, right whale up-calls were detected acoustically in 7 of the 11 mo surveyed (Fig. 3a). Right whales were not acoustically detected during August 2012, October-November 2012, and April 2013. Four months had vocal presence between $\sim 3$ and 5\% (June, July, September 2012; January 2013), while February 2013 had the greatest number of detection days, with a total of $7 \mathrm{~d}$ (25\%) (Fig. 3a). Right whales were acoustically detected on $12.9 \%$ of days in December 2012 and 16.1\% of days in March 2013 (Fig. 3a). Right whale up-calls were detected in every season, though $65 \%$ of the days with right whale acoustic detections occurred in winter (JanuaryMarch 2013), followed by $20 \%$ in autumn (OctoberDecember 2012). Approximately $15 \%$ of the days with right whale acoustic detections at the North Carolina site occurred outside of the nearby mid-Atlantic SMA period.

Right whale up-calls were acoustically detected in the Georgia survey area every season, with presence in every month from June 2012 through March 2013 (Fig. 3b). There were no detections during April 2013. Over the sampled months, December 2012 had the greatest number of detection days, with a total of $29 \mathrm{~d}$ vocal presence out of $31 \mathrm{~d}$ recorded. An initial peak in daily percent presence per month occurred 


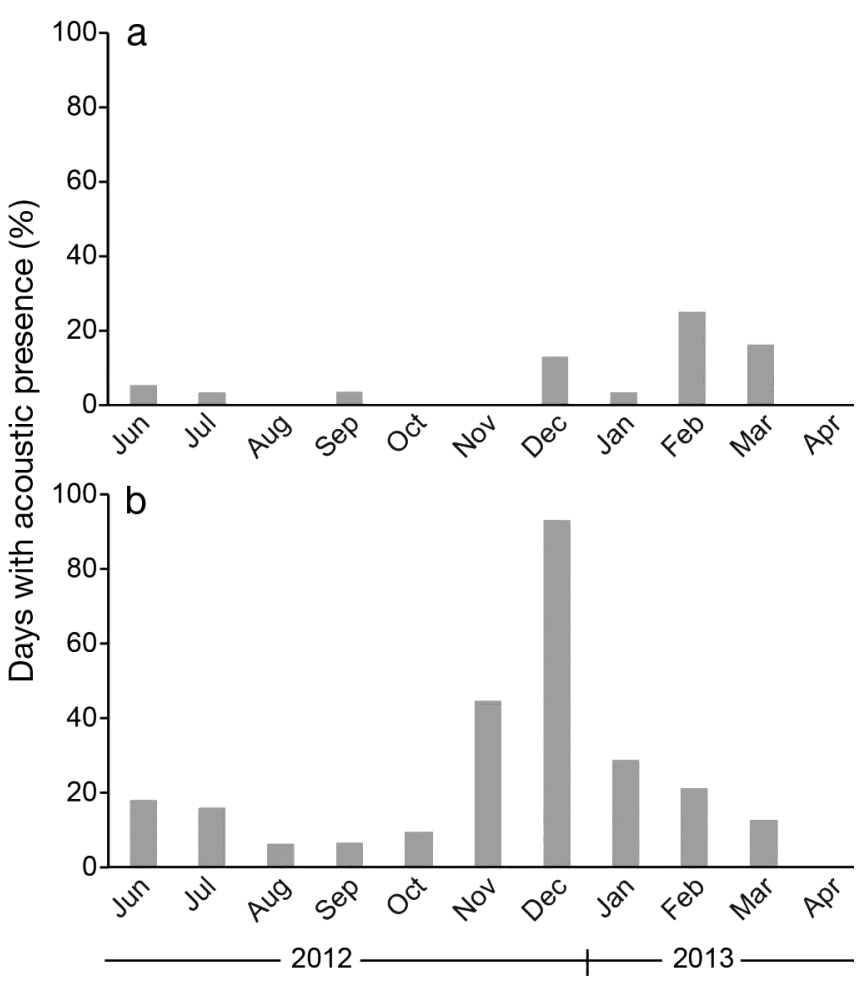

Fig. 3. Percent recorded days in each month with right whale acoustic presence at the (a) North Carolina and (b) Georgia sites

in June and July 2012, with right whales detected on $18.2 \%$ of days in June, and $16.1 \%$ of days in July. Peak detections dropped $<10 \%$ in August through October 2012. A larger, secondary peak occurred in November and December 2012, with right whales detected on $44.8 \%$ of days in November and $93.6 \%$ days in December (Fig. 3b). Daily presence dropped $<30 \%$ in January through March 2013. Subsequently, autumn and winter had the largest proportion of days of right whale occurrence, with 58.4 and $24.7 \%$, respectively. Nearly a third (26\%) of the days with right whale acoustic detections occurred outside the mid-Atlantic SMA period.

\section{DISCUSSION}

\section{Right whale occurrence}

In our passive acoustic survey along the coastal waters of North Carolina and Georgia, right whales were detected during all seasons in the North Carolina and Georgia survey sites. Right whale up-calls were also found in a majority of the months sampled during this study; since right whale up-calls typically have short, environmentally dependent propagation distances (Laurinolli et al. 2003), our data suggest right whales are likely present in the surveyed sites throughout the year. Given how little is known about right whale movements and distribution in the midAtlantic region, our data provide a baseline understanding of right whale occurrence in the nearshore waters of North Carolina and Georgia.

The traditional scientific paradigm of right whale seasonal migrations predicts their presence along the mid-Atlantic US between November and April, likely for traveling to and from the southern calving and northern feeding grounds (Winn et al. 1986, Kenney et al. 2001). Although right whales were detected between November and April, our results did not reveal a bi-modal pattern of occurrence, which one would expect if whales were migrating through the area twice: once during their southward autumnwinter migration, and again during their northward winter-spring migration (as described by Morano et al. 2012). In contrast, our results show that right whales occurred in the North Carolina and Georgia sites outside of the previously documented migratory period (Winn et al. 1986, Kenney et al. 2001). Given the distance between the deployed MARUs, and their acoustic detection range, it is possible right whales occurred within the study sites or farther offshore without being acoustically detected; thus our data may underestimate patterns of right whale occurrence. However, the presence of right whales at the survey sites throughout the year indicates a pattern of presence inconsistent with what has been described as the 'typical' seasonal migratory model (Winn et al. 1986, Kenney et al. 2001). We interpret these results as suggesting that these regions along the mid-Atlantic US could also be important nonmigratory habitat for right whales. The North Carolina site had a fairly consistent low level of presence throughout the survey period when compared to the Georgia site; however, it is unclear if this was due to fewer whales in the area. Peak presence in the Georgia site occurred during the late autumn and early winter months, which overlaps with the occurrence of right whales in the designated critical calving habitat (Kraus et al. 1986, Kenney et al. 2001, Foley et al. 2011). Given our demonstration of right whale presence in the study sites during calving periods, the proximity of the study sites to designated critical calving habitat, and the occurrence of rare calving events outside of the critical calving habitat (Patrician et al. 2009, Waring et al. 2013), it is possible that this region of the mid-Atlantic US is becoming an important area for calving activities (Waring et al. 2013). 
Peak acoustic presence in the North Carolina and Georgia survey areas occurred between November and April, when whales are expected to be migrating through mid-Atlantic US waters (Winn et al. 1986, Kenney et al. 2001). Our data showing peak presence could have been due to a greater number of right whales in the area, increased vocal activity, or both. Our data also show a decreased daily presence at the Georgia site and an increased daily presence at the North Carolina site between January and March. The temporal differences in peak presence between survey areas may reflect the previously described northerly migration in the late winter and early spring, when right whales depart the southern winter calving grounds along the Florida and Georgia coasts and travel to spring feeding areas in the northeast US (Kenney et al. 2001). However, since we do not have observational data to confirm right whale behavior, it is unclear what direction the right whales might have been traveling.

A second, smaller increase in presence occurred in June and July in the Georgia study site, when right whales typically aggregate in the Gulf of Maine and on the Scotian Shelf (Winn et al. 1986). Although visual surveys have detected occasional right whales in mid-Atlantic US coastal areas during summer months, right whales have not been observed in the southeast at that time (Winn et al. 1986, Kenney et al. 2001). It is unclear if our data indicate a rare occurrence or an unknown but more consistent presence of right whales at this time of year. Nevertheless, movement patterns that are not characteristic of the entire right whale population have been documented before, including presence in historical ranges and unexpected habitats (Moore \& Clark 1963, Mate et al. 1997, Jacobsen et al. 2004, Mellinger et al. 2011). Since right whales are not typically observed so far south outside of the calving season, further investigation is needed to understand what is influencing right whale summer distribution along the nearshore waters of Georgia.

\section{Right whale management implications}

Our data demonstrate that right whales are within the North Carolina and Georgia survey areas throughout the year, and this information can be used to evaluate management practices with respect to anthropogenic activities, including offshore energy development. While our North Carolina site is no longer under consideration as a wind energy area, our right whale occurrence data are still relevant and applicable to the current BOEM planning efforts in North Carolina, focusing on the Wilmington W, Wilmington E, and Kitty Hawk wind energy areas (BOEM 2012c). Currently, mitigation protocols are informed by the known or expected right whale seasonal distribution, limiting regional management actions to times when right whales are most likely to be present (BOEM 2012b). These regulatory protocols include: (1) restricted energy development activities during time-area closures, based on the mid-Atlantic SMA time window (1 November30 April); (2) constrained development activities in designated critical habitat during time-area closures; (3) compliance with vessel speed restrictions in the mid-Atlantic SMA; and (4) marine mammal monitoring on survey vessels (BOEM 2012b). Since at least some right whales are present in the North Carolina and Georgia survey areas outside of the designated mid-Atlantic SMA time period, right whales in these areas would be at risk of exposure to lethal and sub-lethal threats from anthropogenic activities when restrictions are not in effect. Additionally, mid-Atlantic SMA restrictions are limited to geographic areas within a 20 nautical mile (nmi; $37 \mathrm{~km}$ ) radius of major ports (NOAA 2008). Right whales may occupy habitat beyond the $20 \mathrm{nmi}$ radius, as evidenced by the data collected from the North Carolina survey site, which is located $\sim 30 \mathrm{nmi}$ (55.6 km) offshore. Therefore, right whales occurring outside of the mid-Atlantic SMA region would be at risk of exposure to all threats associated with wind energy development activities. Additionally, right whales located in both the North Carolina and Georgia survey sites will not be afforded the same protections as whales located within the critical calving habitat. Thus, enacting management decisions based solely on the 'typical' right whale seasonal migration may not provide adequate protection for right whales in the surveyed mid-Atlantic regions.

The loss of even one individual right whale, particularly a reproductive female, can have severe consequences to the recovery of this population from the threat of extinction (Caswell et al. 1999, Fujiwara \& Caswell 2001, Kraus et al. 2005). Preventing right whale mortality is of utmost importance for the conservation of this species, and given the risk of exposure to threats associated with anthropogenic activities, we suggest our data warrants an evaluation of many previously established management protocols. The current SMA geographic coverage in the midAtlantic US may need to be amended to include other areas of suitable right whale habitat. Our results 
demonstrate right whale presence throughout the year in the North Carolina survey site, suggesting right whales may occur outside the $20 \mathrm{nmi}$ radius of SMA protection in North Carolina. Extending the protective coverage to a minimum of $30 \mathrm{nmi}$, as suggested in Schick et al. (2009), would potentially mitigate vessel strikes, since reduced vessel speeds decrease the risk of ship-strike mortality (Vanderlaan \& Taggart 2007, Conn \& Silber 2013). The SMA time period may also need to be extended to include other seasons when right whales may occur in the area (Pace 2011). Lastly, our data could be used to consider the extension of critical habitat boundaries into areas along the mid-Atlantic migratory corridor (NOAA 2010). Right whale presence throughout the year in mid-Atlantic coastal waters might indicate that this region contains features important for right whale survival and reproduction.

Although our data show right whale vocal presence in all seasons, our 11 mo survey period is not long enough to elucidate long-term seasonal patterns of distribution and inter-annual variability. Other processes, such as prey distribution and environmental factors, are known to affect the movement patterns of right whales, and these patterns certainly vary over time (Wishner et al. 1995, Baumgartner et al. 2003, Keller et al. 2006, Pendleton et al. 2009). Monitoring efforts conducted over multiple years would not only reveal further information about right whale spatial and temporal patterns (e.g. Morano et al. 2012), but could also address questions regarding demography, abundance, and habitat use. Given how little is known about right whales in the midAtlantic migratory corridor, we recommend longterm monitoring efforts be conducted along the North Carolina and Georgia coasts in the midAtlantic US. We further recommend managers consider the use of passive acoustic monitoring in conjunction with visual survey efforts. Visual surveys provide observational data that inform questions regarding demography and behavior of right whale individuals, which cannot be addressed with passive acoustic data. However, passive acoustic monitoring is a data-rich and cost-effective tool for monitoring right whales over extended periods, particularly when right whale occurrence is infrequent, and when aerial surveys cannot be performed due to poor visibility or inclement weather (Mellinger et al. 2007, Clark et al. 2010). Passive acoustic monitoring, in conjunction with visual survey efforts, would provide a more comprehensive understanding of right whale distribution and habitat characterization to better inform management decisions.
Acknowledgements. We thank C. Diamond, E. Griffiths, M. Loman, K. Palmer, C. Pelkie, D. Salisbury, and A. Warde for assistance in analysis; J. Michalec for deploying and recovering the recording equipment; and J. Barry of the Cornell Statistical Consulting Group and M. Pitzrick for detector validation efforts. We also thank R. Charif, C. Diamond, J. Tielens, W. McLellan, and 2 anonymous reviewers for comments on the manuscript. Funding for this project was provided by the US Bureau of Ocean Energy Management (contract M10PC00087) and the National Oceanic and Atmospheric Administration, through the National Oceanographic Partnership Program.

\section{LITERATURE CITED}

Barco SG, McLellan WA, Allen JM, Asmutis-Silvia RA and others (2002) Population identity of humpback whales (Megaptera novaeangliae) in the waters of the US midAtlantic states. J Cetacean Res Manag 4:135-141

Baumgartner MF, Cole TVN, Campbell RG, Teegarden GJ, Durbin EG (2003) Associations between North Atlantic right whales and their prey, Calanus finmarchicus, over diel and tidal time scales. Mar Ecol Prog Ser 264:155-166

Bioacoustics Research Program (2012) XBAT R6: extensible bioacoustics tool. www.birds.cornell.edu/brp/software/ xbat-introduction (accessed 18 Sep 2014)

BOEM (Bureau of Ocean Energy Management) (2012a) Atlantic OCS proposed geological and geophysical activities: Mid-Atlantic and South Atlantic Planning Areas Draft Programmatic Environmental Impact Statement, Vol. 1. OCS EIS/EA BOEM 2012-005:1-550

BOEM (Bureau of Ocean Energy Management) (2012b) Atlantic OCS proposed geological and geophysical activities: Mid-Atlantic and South Atlantic Planning Areas Biological Assessment. BOEM, New Orleans, LA

BOEM (Bureau of Ocean Energy Management) (2012c) Commercial leasing for wind power on the outer continental shelf offshore North Carolina - call for information and nominations. Fed Regist 77:74204-74213

Calupca TA, Fristrup KM, Clark CW (2000) A compact digital recording system for autonomous bioacoustic monitoring. J Acoust Soc Am 108:2582

> Cassoff RM, Moore KM, McLellan WA, Barco SG, Rotstein DS, Moore MJ (2011) Lethal entanglement in baleen whales. Dis Aquat Org 96:175-185

> Caswell H, Fujiwara M, Brault S (1999) Declining survival probability threatens the North Atlantic right whale. Proc Natl Acad Sci USA 96:3308-3313

Clapham PJ, Young SB, Brownell RL (1999) Baleen whales: conservation issues and the status of the most endangered populations. Mammal Rev 29:37-62

Clark CW (1982) The acoustic repertoire of the Southern right whale: a quantitative analysis. Anim Behav 30:1060-1071

Clark CW, Gillespie D, Nowacek DP, Parks SE (2007) Listening to their world: acoustics for monitoring and protecting right whales in an urbanized ocean. In: Kraus SD, Rolland RM (eds) The urban whale: North Atlantic right whales at the crossroads. Harvard University Press, Cambridge, MA, p 333-357

Clark CW, Ellison WT, Southall BL, Hatch L, Van Parijs SM, Frankel A, Ponirakis D (2009) Acoustic masking in marine ecosystems: intuitions, analysis, and implication. Mar Ecol Prog Ser 395:201-222 
Clark CW, Brown MW, Corkeron PJ (2010) Visual and acoustic surveys for North Atlantic right whales, Eubalaena glacialis, in Cape Cod Bay, Massachusetts, 2001-2005: management implications. Mar Mamm Sci 26:837-854

Cole TVN, Hamilton P, Henry AG, Duley P, Pace RM, White BN, Frasier T (2013) Evidence of a North Atlantic right whale Eubalaena glacialis mating ground. Endang Species Res 21:55-64

Conn P, Silber G (2013) Vessel speed restrictions reduce risk of collision-related mortality for North Atlantic right whales. Ecosphere 4:43

Figueroa H, Robbins M (2008) XBAT: an open-source extensible platform for bioacoustic research and monitoring. In: Frommolt K, Bardeli R, Clausen M (eds) Computational acoustics for assessing biodiversity. Proc Int Expert Meet IT-based Detection Bioacoustical Patterns, BfN Skripten, Bonn, p 143-155

Firestone J, Lyons SB, Wang C, Corbett JJ (2008) Statistical modeling of North Atlantic right whale migration along the mid-Atlantic region of the eastern seaboard of the United States. Biol Conserv 141:221-232

- Foley H, Holt R, Hardee R, Nilsson P and others (2011) Observations of a western North Atlantic right whale (Eubalaena glacialis) birth offshore of the protected southeast US critical habitat. Mar Mamm Sci 27: E234-E240

> Fujiwara M, Caswell H (2001) Demography of the endangered North Atlantic right whale. Nature 414: $537-541$

> Hatch LT, Clark CW, Van Parijs SM, Frankel AS, Ponirakis DW (2012) Quantifying loss of acoustic communication space for right whales in and around a U.S. National Marine Sanctuary. Conserv Biol 26:983-994

Jacobsen K, Marx M, OIen N (2004) Two-way trans-Atlantic migration of a North Atlantic right whale (Eubalaena glacialis). Mar Mamm Sci 20:161-166

Keller CA, Ward-Geiger LI, Brooks WB, Slay CK, Taylor CR, Zoodsma BJ (2006) North Atlantic right whale distribution in relation to sea-surface temperature in the southeastern United States calving grounds. Mar Mamm Sci 22:426-445

Kenney RD, Winn HE, Macaulay MC (1995) Cetaceans in the Great South Channel, 1979-1989: right whale (Eubalaena glacialis). Cont Shelf Res 15:385-414

Kenney RD, Mayo CA, Winn HE (2001) Migration and foraging strategies at varying spatial scales in western North Atlantic right whales: a review of hypotheses. J Cetacean Res Manage 2:251-260

Knowlton AR, Kraus SD (2001) Mortality and serious injury of northern right whales (Eubalaena glacialis) in the western North Atlantic Ocean. J Cetacean Res Manag 2: 193-208

Knowlton AR, Ring JB, Russell B (2002) Right whale sightings and survey effort in the mid-Atlantic region: migratory corridor, time frame, and proximity to port entrances. A report submitted to the NMFS ship strike working group. NMFS, Silver Spring, MD

Kraus SD (1990) Rates and potential causes of mortality in North Atlantic right whales (Eubalaena glacialis). Mar Mamm Sci 6:278-291

Kraus SD, Prescott JH, Knowlton AR, Stone GS (1986) Migration and calving of right whales (Eubalaena glacialis) in the western North Atlantic. Rep Int Whaling Comm 10:139-144
Kraus SD, Brown MW, Caswell H, Clark CW and others (2005) North Atlantic right whales in crisis. Science 309: 561-562

Kraus SD, Pace RM, Frasier TR (2007) High investment, low return: the strange case of reproduction in Eubalaena glacialis. In: Kraus SD, Rolland RM (eds) The urban whale: North Atlantic right whales at the crossroads. Harvard University Press, Cambridge, MA, p 172-199

Laist DW, Knowlton AR, Mead JG, Collet AS, Podesta M (2001) Collisions between ships and whales. Mar Mamm Sci 17:35-75

Laurinolli MH, Hay AE, Desharnais F, Taggart CT (2003) Localization of North Atlantic right whale sounds in the Bay of Fundy using a sonobuoy array. Mar Mamm Sci 19: 708-723

> Madsen PT, Wahlberg M, Tougaard J, Lucke K, Tyack P (2006) Wind turbine underwater noise and marine mammals: implications of current knowledge and data needs. Mar Ecol Prog Ser 309:279-295

Mate BR, Nieukirk SL, Kraus SD (1997) Satellite-monitored movements of the northern right whale. J Wildl Manage 61:1393-1405

McDonald MA, Moore SE (2002) Calls recorded from North Pacific right whales (Eubalaena japonica) in the eastern Bering Sea. J Cetacean Res Manage 4:261-266

Mellinger DK (2004) A comparison of methods for detecting right whale calls. Can Acoust 32:55-65

Mellinger DK, Stafford KM, Moore SE, Dziak RP, Matsumoto H (2007) An overview of fixed passive acoustic observation methods for cetaceans. Oceanography 20: $36-45$

> Mellinger DK, Nieukirk SL, Klinck K, Klinck H, Dziak RP, Clapham PJ, Brandsdottir B (2011) Confirmation of right whales near a nineteenth-century whaling ground east of southern Greenland. Biol Lett 7:411-413

> Moore JC, Clark E (1963) Discovery of right whales in the Gulf of Mexico. Science 141:269-270

Morano JL, Rice AN, Tielens JT, Estabrook BJ, Murray A, Roberts B, Clark CW (2012) Acoustically detected yearround presence of right whales in an urbanized migration corridor. Conserv Biol 26:698-707

Mussoline SE, Risch D, Hatch LT, Weinrich MT and others (2012) Seasonal and diel variation in North Atlantic right whale up-calls: implications for management and conservation in the northwestern Atlantic Ocean. Endang Species Res 17:17-26

NMFS (National Marine Fisheries Service) (2005) Recovery plan for the North Atlantic right whale (Eubalaena glacialis). Office of Protected Resources, NMFS, Silver Spring, MD

NMFS (National Marine Fisheries Service) (2012) Annual Report of a comprehensive assessment of marine mammal, marine turtle, and seabird abundance and spatial distribution in U.S. waters of the western North Atlantic Ocean, available at: www.nefsc.noaa.gov/psb/AMAPPS/ docs/NMFS_AMAPPS_2012_annual_report_FINAL.pdf

NOAA (National Oceanic and Atmospheric Administration) (1994) Designated critical habitat; northern right whales. Fed Reg 203:28805-28835

NOAA (National Oceanic and Atmospheric Administration) (2008) Endangered fish and wildlife: final rule to implement speed restrictions to reduce the threat of ship collisions with North Atlantic right whales. Fed Reg 73: 60173-60191 
NOAA (National Oceanic and Atmospheric Administration) (2010) Endangered and threatened wildlife and designating critical habitat for the endangered North Atlantic right whale. Fed Reg 75:61690-61691

Pace RM (2011) Frequency of whale and vessel collisions on the US eastern seaboard: ten years prior and two years post ship strike rule. Northeast Fish Sci Cent Ref Doc, Woods Hole, MA

Parks SE, Clark CW (2007) Acoustic communication: social sounds and the potential impacts of noise. In: Kraus SD, Rolland RM (eds) The urban whale: North Atlantic right whales at the crossroads. Harvard University Press, Cambridge, MA, p 310-332

Parks SE, Tyack PL (2005) Sound production by North Atlantic right whales (Eubalaena glacialis) in surface active groups. J Acoust Soc Am 117:3297-3306

Patrician MR, Biedron IS, Esch HC, Wenzel FW and others (2009) Evidence of a North Atlantic right whale calf (Eubalaena glacialis) born in northeastern US waters. Mar Mamm Sci 25:462-477

Pendleton DE, Pershing AJ, Brown MW, Mayo CA, Kenney RD, Record NR, Cole TVN (2009) Regional-scale mean copepod concentration indicates relative abundance of North Atlantic right whales. Mar Ecol Prog Ser 378: 211-225

Pettis H (2013) North Atlantic Right Whale Consortium 2013 annual report card. Rep North Atlantic Right Whale Consortium, November 2013

Rolland RM, Parks SE, Hunt KE, Castellote M and others (2012) Evidence that ship noise increases stress in right whales. Proc R Soc B 279:2363-2368

Schick RS, Halpin PN, Read AJ, Slay CK and others (2009) Striking the right balance in right whale conservation. Can J Fish Aquat Sci 66:1399-1403

Silber GK, Bettridge S (2010) Vessel operations in right whale protection areas in 2009. NOAA Tech Memo NMFS-OPR-44. Office of Protected Resources, NMFS, Silver Spring, MD

Urazghildiiev IR, Clark CW, Krein TP, Parks SE (2009) Detection and recognition of North Atlantic right whale contact calls in the presence of ambient noise. IEEE J Ocean Eng 34:358-368

Editorial responsibility: Brendan Godley,

University of Exeter, Cornwall Campus, UK van der Hoop JM, Vanderlaan ASM, Taggart CT (2012) Absolute probability estimates of lethal vessel strikes to North Atlantic right whales in Roseway Basin, Scotian Shelf. Ecol Appl 22:2021-2033

> van der Hoop JM, Moore MJ, Barco SG, Cole TVN and others (2013) Assessment of management to mitigate anthropogenic effects on large whales. Conserv Biol 27: 121-133

van der Hoop JM, Vanderlaan ASM, Cole TVN, Henry AG and others (2015) Vessel strikes to large whales before and after the 2008 Ship Strike Rule. Conserv Lett 8:24-32

> Van Parijs SM, Clark CW, Sousa-Lima RS, Parks SE, Rankin S, Risch D, Van Opzeeland IC (2009) Management and research applications of real-time and archival passive acoustic sensors over varying temporal and spatial scales. Mar Ecol Prog Ser 395:21-36

> Vanderlaan ASM, Taggart CT (2007) Vessel collisions with whales: the probability of a lethal injury based on vessel speed. Mar Mamm Sci 23:144-156

Waring GT, Josephson E, Maze-Foley K, Rosel PE (2013) U.S. Atlantic and Gulf of Mexico marine mammal stock assessments - 2012, Vol. 1. NMFS, NOAA, Woods Hole, MA

- Weilgart LS (2007) The impacts of anthropogenic ocean noise on cetaceans and implications for management. Can J Zool 85:1091-1116

Whitt AD, Dudzinski K, Laliberté JR (2013) North Atlantic right whale distribution and seasonal occurrence in nearshore waters off New Jersey, USA, and implications for management. Endang Species Res 20:59-69

Wiley DN, Thompson M, Pace RM, Levenson J (2011) Modeling speed restrictions to mitigate lethal collisions between ships and whales in the Stellwagen Bank National Marine Sanctuary, USA. Biol Conserv 144: 2377-2381

Winn HE, Price CA, Sorensen PW (1986) The distributional biology of the right whale (Eubalaena glacialis) in the western North Atlantic. Rep Int Whaling Comm 10:129-138

- Wishner KF, Schoenherr JR, Beardsley R, Chen C (1995) Abundance, distribution and population structure of the copepod Calanus finmarchicus in a springtime right whale feeding area in the southwestern Gulf of Maine. Cont Shelf Res 15:475-507

Submitted: June 10, 2014; Accepted: June 11, 2015

Proofs received from author(s): September 8, 2015 